\title{
Default options, incentives and food choices: evidence from elementary-school children
}

\author{
David Just ${ }^{1}$ and Joseph Price ${ }^{2, *}$ \\ 'Department of Applied Economics and Management, Cornell University, Ithaca, NY, USA: ${ }^{2}$ Department of \\ Economics, Brigham Young University, 162 FOB, Provo, UT 84602, USA
}

Submitted 18 July 2012: Final revision received 26 March 2013: Accepted 27 March 2013: First published online 28 May 2013

\begin{abstract}
Objective: To examine whether requiring children to place fruits and vegetables on their lunch trays increases consumption of these items.

Design: Observational study that exploited naturally occurring variation between two school districts and a pre-post observational study at schools that changed their lunch policy mid-year.

Setting: Fifteen elementary schools from two school districts, one requiring students to place a fruit or vegetable on their tray and one that does not. In addition, three schools that implemented a default option part way through the school year.

Subjects: Students at eighteen elementary schools (41374 child-day observations) across the two experiments.

Results: Requiring that fruits and vegetables be placed on each child's tray increased the fraction of children who ate a serving of fruits or vegetables by 8 percentage points $(P<0 \cdot 01)$ but led to an extra 0.7 servings being thrown away per lunch served $(P<0 \cdot 01)$. The default option approach cost $\$ \mathrm{US} 1.72$ to get one additional child to eat one serving of fruits and vegetables for $1 \mathrm{~d}$. However, when default options were combined with a small rewards programme the efficacy of both interventions increased.

Conclusions: A default option, as a stand-alone programme, had only a limited impact on fruit and vegetable consumption but was much less cost-effective than other approaches. Schools requiring children to take fruits and vegetables with their lunch might consider adopting additional interventions to ensure that the additional items served do not end up being thrown away.
\end{abstract}

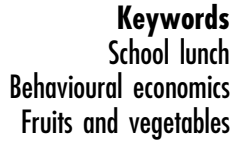

Keywords Behavioural economics Fruits and vegetables
Default options have had a powerful influence on people's decisions to donate organs, invest in their retirement and select certain health insurance plans ${ }^{(1-3)}$. Default options can influence behaviour through behavioural inertia or by communicating social norms ${ }^{(4,5)}$. Successful applications of default options are often binary decisions that are unfamiliar, made infrequently and require no subsequent initiative. This is in stark contrast to food choice structure, where individuals have many options (all of which are very familiar), make repeated decisions throughout each day and must play an active role in the decision (often preparing the food themselves and always actively placing the food in their mouth).

The Healthy, Hunger-Free Kids Act of 2010 provides new guidelines for school lunches. As part of these guidelines, each reimbursable meal will need to include a serving of both fruits and vegetables and the child must take one or the other. Schools will need to ensure that these items are on each student's tray. Prior to the change, reimbursable meals were required to have three food groups represented, with one being protein. Under the previous guidelines schools chose whether they would use an 'offer' or 'serve' approach to providing fruits and vegetables as part of the school lunch $^{(6)}$. The new guidelines will lead to a dramatic shift for schools that have historically allowed children to choose whether or not to place fruits and vegetables on their tray. This new policy represents a default option in which the items go on the child's tray by default, but the child can choose whether or not to discard the item.

Despite the scores of articles examining the various factors that influence children's intake of fruits and vegetables, the majority of these studies focus on how sociodemographic characteristics, socio-economic status or practices in the home contribute to eating habits ${ }^{(7)}$. Within a school lunch context, many of these factors are fixed and thus not useful in guiding children to healthier food choices. Factors such as nutrition education, choice environment and the design of the school lunch decision itself may be important factors and have recently received much greater attention ${ }^{(8-10)}$.

The presence of a default is closely related to the availability of fruits and vegetables in the lunch line. Generally, availability is found to have a substantial 
impact on consumption, accounting for up to $35 \%$ of the variation in consumption of fruits and vegetables ${ }^{(11)}$. In contrast, the presence of self-serve salad bars in elementary schools is not associated with a meaningful increase in fruit and vegetable consumption. Students who attended a school with a salad bar present consumed an average of $4 \mathrm{~g}$ more (less than $3 \%$ of a medium apple) fruits and vegetables than those whose school had no salad bar, although the variety of items offered at salad bars was positively related to fruit and vegetable consumption ${ }^{(12)}$. Other interventions that involved the students in the cultivation or preparation of fruits and vegetables have shown substantial impacts on consumption ${ }^{(13)}$.

Previous studies have found that awareness campaigns and incentives increase fruit and vegetable consumption among adults and children ${ }^{(14,15)}$. A study of price manipulation found that relative price reductions of lowfat snacks compared with snacks with higher fat levels influenced both child and adult consumption patterns ${ }^{(16)}$. In addition to the impact of defaults, in the present study we tested the degree to which the presence of default options increased the efficacy of an incentive programme. We hypothesized that requiring that a fruit or vegetable be placed on the tray should lead the child who otherwise may have passed it up in the line to have more time to contemplate whether or not to consume the fruit or vegetable. This added time may also make incentives or other inducements more effective. Not surprisingly, studies employing peer modelling and rewards-based intervention have also found success. Students who received rewards for eating fruits and vegetables at school increased their intake substantially. This further translated into significant increases in fruit and vegetable consumption at home ${ }^{(14)}$. It should be noted that our incentives programme is just one of many possible complementary interventions that could be combined with default options. We included these results to provide insight into the degree to which default options can be coupled with other interventions to provide synergistic effects.

Waste of fruits and vegetables is often a concern given their relatively high cost and the relatively low consumption rates. Previous estimates for at-home food waste run from $12 \cdot 7 \%$ to $25 \cdot 0 \%$, while school lunch waste estimates were found to range from $24 \cdot 3 \%$ to $34 \cdot 9 \%{ }^{(17-19)}$. One would expect that a policy requiring fruits and vegetables to be on each tray would increase the amount wasted. These historical figures will aid in the comparison of wastage rates as the default option is discussed.

\section{Methods}

We used data from two different settings to examine the impact of requiring children to take a serving of fruits or vegetables on whether children actually consume more fruits and vegetables. In both settings, each student's tray was observed visually at the end of lunch. Fruits and vegetables were served in special pre-portioned cups when they would not otherwise leave a peel or core behind. The student's sex and grade were also recorded. We used these observations to calculate the servings of fruits and vegetables each child took, ate and threw away. All of the observations were recorded in increments of half a serving. Other studies have successfully employed visual estimation of cafeteria consumption and waste ${ }^{(14,20)}$ and we found an average inter-rater reliability of 0.781 using our data collection approach.

For both studies we collected consumption and waste patterns of every student receiving a school lunch. Because our observation method did not affect the normal flow of lunch, it is less likely to affect a student's consumption of fruits and vegetables. When asked by students, observers were instructed to respond that they are doing a study about what kids eat at lunch with no reference to fruits or vegetables. For both studies, when examining the impact of the default option, data were analysed using clustered regression, with standard errors clustered at the school-date level.

The outcome variables that we measured included the number of servings of fruits or vegetables taken by a child in a day, the number of servings eaten by a child in a day and the number of servings thrown away by a child in a day. We included three versions of each regression model: (i) no controls; (ii) controls for grade, sex, size of school and the fraction of children qualifying for a free or reduced-price lunch; and (iii) the same controls and additionally controlling for the popularity of the most popular item being offered that day. Popularity was determined by calculating the fraction of children who ate at least one serving of each item on the days in our sample that it was offered. For each regression model we included a dummy variable that was equal to 1 in schools with the default in place. The coefficient on this variable served as our estimated treatment effect. We considered $P<0.05$ to be statistically significant.

\section{Study 1 (comparison between districts)}

The first experiment was part of a larger project examining the effect of incentives on healthy eating during school lunch. For this experiment, we collected data from fifteen elementary schools in Utah located in two adjacent and demographically similar school districts. One of these school districts had a policy that required every child to have at least one serving of fruits or vegetables on his/her tray. These items were placed automatically on each student's tray although students were still allowed a choice of which entrée, side dishes and beverage they wanted. The other district's policy allowed children to choose whether or not they wanted to place fruits or vegetables on their tray. The two districts were very similar with regard to policies directly impacting eating behaviours. Neither district sold competitive or à la carte foods. 
Neither district provided snacks for the children before lunch, nor did they have vending machines in their buildings. All of the schools studied held recess immediately following lunch. The schools in our sample from the two districts had the same fraction of students receiving a free or reduced-price lunch (about $54 \%$ on average).

At each school, we collected at least $5 \mathrm{~d}$ of baseline data and $5 \mathrm{~d}$ of data during which we gave a small reward to children who ate at least one serving of fruits or vegetables. The data from this first experiment included information on 175 school-days with 29880 child-day observations during the baseline period and 17534 observations during the treatment period in which students could receive a small reward for eating at least one serving of fruits or vegetables. We used both periods of data in our analysis. The baseline data provided information on the change in behaviour when just the default option was in place. The combination of baseline and treatment data allowed us to test if the effect of providing rewards was larger when a default option was already in place.

For the rewards programme, the type of reward used was randomly assigned to each school and included: (i) receive a lottery ticket for a prize immediately; (ii) receive a quarter (25 cents) immediately; (iii) receive a lottery ticket for a prize in two weeks; (iv) receive a quarter in two weeks; or (v) receive a nickel (5 cents) immediately. Children were eligible to earn a prize each day that they ate at least one serving of fruits or vegetables. Students learned about the rewards on the morning announcement each day and signs that were posted in the cafeteria. For schools with a delayed prize, students wrote their name on a ticket and left it in a jar and the prizes were delivered to each student two weeks later. Just and Price ${ }^{(21)}$ use the same data to examine how the response to incentives varied across the different types of rewards. For our analysis, we combined the different rewards into a single measure which represents the average effect across the different types of prizes. We use the rewards programme in the present paper as an example of a programme that could be used in conjunction with a default option policy during lunch.

In order to analyse the interaction of defaults and incentives, we used both a fixed-effects and a randomeffects model. Dependent variables included the number of servings of fruits or vegetables eaten by a child in a day and the number of servings thrown away by each child. Each regression model included controls for grade, sex, the popularity of the most popular item being offered that day (calculated as before) and day of the week as fixed effects. Standard errors were clustered at the school-date level.

\section{Study 2 (within-school comparison)}

The second experiment included a sample of three schools that implemented a default option policy during the school year in preparation for future changes in the school lunch guidelines. At these schools, the policy was implemented to mimic the future lunch guidelines in which children were allowed to choose which fruit or vegetable items they wanted but needed to place at least one serving of fruits or vegetables on their tray. For this set of schools, we were able to observe the children's eating patterns both on the days with and the days without the default option in place. For each school, we had $4-9 \mathrm{~d}$ of data when there was no default option and 3-10 d where there was a default option. This allowed us to control for all of the school- and districtlevel characteristics that might bias the results of study 1 .

\section{Results}

\section{Study 1 (comparison across districts)}

Our first setting involved data from two school districts, one of which had a requirement for children to take at least one serving of fruits or vegetables, and one which did not. In columns 2 and 3 of Table 1, we provide the difference in consumption patterns between the two school districts. Table 1 not only presents the percentage of students who ate at least one serving, but also presents the percentage of servings that got thrown away. We found almost no difference between the two districts in the fraction of children who actually ate a serving of fruits or vegetables ( $35 \% v .33 \%$ of children; NS). However, the number of servings thrown away per child was about twice as high in the school district with a default option $(0 \cdot 17 v \cdot 0 \cdot 40$; statistically significant at the $1 \%$ level $)$. It is also important to note the possibility that schools with the default option led to children only tasting some new fruits and vegetables, without actually eating a full serving. However, when we compared the percentage of students who ate at least a partial serving of fruits and vegetables

Table 1 The effect of requiring elementary-school students to place fruits or vegetables on their tray at lunchtime on consumption and waste

\begin{tabular}{|c|c|c|c|c|c|c|c|c|c|c|}
\hline & \multicolumn{5}{|c|}{ Cross-district comparison } & \multicolumn{5}{|c|}{ Within-school comparison } \\
\hline & \multicolumn{2}{|c|}{ Optional } & \multicolumn{2}{|c|}{ Required } & \multirow[b]{2}{*}{$P$ value } & \multicolumn{2}{|c|}{ Optional } & \multicolumn{2}{|c|}{ Required } & \multirow[b]{2}{*}{$P$ value } \\
\hline & Mean & SD & Mean & SD & & Mean & SD & Mean & SD & \\
\hline Ate one serving (\%) & $34 \cdot 8$ & $8 \cdot 2$ & $32 \cdot 9$ & $15 \cdot 0$ & 0.474 & $20 \cdot 4$ & $6 \cdot 2$ & $27 \cdot 9$ & $6 \cdot 5$ & 0.001 \\
\hline Servings wasted & $0 \cdot 172$ & 0.053 & 0.402 & $0 \cdot 181$ & 0.000 & $0 \cdot 173$ & $0 \cdot 067$ & 0.924 & $0 \cdot 159$ & 0.000 \\
\hline Observations & \multicolumn{2}{|c|}{10208} & \multicolumn{2}{|c|}{19672} & & \multicolumn{2}{|c|}{6142} & \multicolumn{2}{|c|}{5352} & \\
\hline
\end{tabular}

'Ate one serving' is the fraction of students who ate at least one serving of fruits or vegetables; 'servings wasted' is the average number of servings that each student threw away; 'optional' and 'required' refer to whether students were required to take a serving of fruits or vegetables as part of their school-provided lunch. 
Table 2 Regression estimates of the effect of requiring elementary-school students to place fruits or vegetables on their tray at lunchtime on consumption and waste

\begin{tabular}{|c|c|c|c|c|c|c|c|c|}
\hline & \multicolumn{4}{|c|}{ Cross-district comparison } & \multicolumn{4}{|c|}{ Within-school comparison } \\
\hline & \multicolumn{2}{|c|}{ Ate one serving } & \multicolumn{2}{|c|}{ Servings wasted } & \multicolumn{2}{|c|}{ Ate one serving } & \multicolumn{2}{|c|}{ Servings wasted } \\
\hline & Mean & SE & Mean & SE & Mean & SE & Mean & SE \\
\hline Fruit/vegetable required & $0 \cdot 018^{\star \star}$ & 0.007 & $0 \cdot 243^{\star \star}$ & 0.007 & $0.077^{* *}$ & $0 \cdot 018$ & $0.744^{\star *}$ & 0.026 \\
\hline Grade & $0.009^{\star \star}$ & 0.002 & $-0 \cdot 016^{\star \star}$ & 0.002 & 0.003 & 0.003 & $-0 \cdot 013^{\star \star}$ & 0.003 \\
\hline Male & $-0 \cdot 085^{\star \star}$ & 0.005 & $-0 \cdot 017^{\star \star}$ & 0.006 & $-0.070^{\star \star}$ & $0 \cdot 011$ & $-0.097^{\star \star}$ & 0.015 \\
\hline School's FRPL rate & $-0 \cdot 056^{\star \star}$ & 0.020 & 0.002 & 0.021 & & & & \\
\hline School size (100s) & $-0 \cdot 026^{\star \star \star}$ & 0.006 & $-0 \cdot 019^{\star \star}$ & $0 \cdot 006$ & & & & \\
\hline School fixed effects & \multirow{2}{*}{\multicolumn{2}{|c|}{29880}} & \multirow{2}{*}{\multicolumn{2}{|c|}{29880}} & \multirow{2}{*}{\multicolumn{2}{|c|}{$\begin{array}{c}x \\
11494\end{array}$}} & \multirow{2}{*}{\multicolumn{2}{|c|}{$\begin{array}{c}x \\
11494\end{array}$}} \\
\hline Observations & & & & & & & & \\
\hline
\end{tabular}

'Ate one serving' is the fraction of students who ate at least one serving of fruits or vegetables; 'servings wasted' is the average number of servings that each student threw away. Each regression model also includes controls for day of the week and popularity of the most popular fruit or vegetable being served that day. The school's FRPL rate is the fraction of students receiving a free or reduced-price lunch. Standard errors are clustered at the school-date level.

${ }^{*}$ and ${ }^{* *}$ indicate statistical significance at the $5 \%$ and $1 \%$ level, respectively.

between schools in the two districts, we found the fraction of children eating at least a partial serving to differ by only 0.3 percentage points $(40 \cdot 7 \% v .41 \cdot 1 \%$; NS).

In columns 2 and 3 of Table 2 we provide regression estimates of the comparisons in Table 1 . The regression estimates allow us to control for observable differences between the two school districts as well as information about each individual student and the fruits and vegetables being served that day. We include controls for grade, sex, day of the week, school size and the percentage of students who receive subsidized lunches. We also include a control for the popularity of the most popular fruit or vegetable being served that day, which is measured using the fraction of children who ate at least one serving of the item across all of the days the item is offered.

The results in the second and third columns of Table 2 indicate that children in the district with the default option were 1.8 percentage points less likely to eat a serving of fruits or vegetables but also threw away an additional $0 \cdot 243$ servings of fruits and vegetables per lunch served (controlling for demographic characteristics of the students and schools). The coefficients on the control variables indicate that younger children, boys and children at poorer and larger schools were all less likely to eat at least one serving of fruits and vegetables during lunch.

\section{Study 2 (witbin-school analysis)}

Our second setting was a situation in which a set of schools decided to change their default option policy in preparation for changes in the US Department of Agriculture's guidelines about reimbursable meals. In columns 5 and 6 of Table 1, we provide two measures of the food choices children make at lunch before and after the change in the policy. We found that introduction of the default option increased the fraction of children who ate at least one serving of fruits or vegetables by 8 percentage points (from $20 \%$ to $28 \%$; statistically significant at the $1 \%$ level). We also found that introduction of the default option increased the fraction of children trying at least a partial serving of fruits and vegetables by 10 percentage points (from $25 \%$ to $35 \%$; statistically significant at the $1 \%$ level).

The default option also increased the number of servings of fruits and vegetables that the school served from 0.42 to 1.29 servings per child (an increase of 0.86 servings) with the number of servings being thrown away per child increasing from 0.17 to 0.92 (a more than fourfold increase; statistically significant at the $1 \%$ level). The increase in the number of servings being placed on each child's tray was driven by a large increase in the fraction of students eating one serving (increasing from $31 \%$ up to $70 \%$ ) as well as an increase in the fraction of children eating two or more servings (increasing from $6 \%$ to $28 \%$ ). However, as more items were served the fraction of items being thrown away more than doubled for those students taking just one serving (from 39\% up to $82 \%$ ) and also increased for those students taking two or more servings (from $45 \%$ up to $60 \%$ ).

Based on school records, we found that the average serving of fruits and vegetables costs about $\$$ US $0 \cdot 20$. This means that requiring an additional 100 children to take one serving of fruits or vegetables would require serving eighty-six additional servings of these items (with an additional cost of $\$$ US $17 \cdot 20$ ) but would result in only eight additional children eating at least one serving of fruits or vegetables. This translates into a cost of \$US 1.72 to get one additional child to eat one additional serving for $1 \mathrm{~d}$. While it is hard to find equivalent measures to compare this with other interventions, the small rewards programme implemented by Just and Price ${ }^{(21)}$, which gave children direct incentives for fruit and vegetable consumption, cost about \$US 0.35 to produce a comparable short-run impact. A discussion of the national impacts follows in the discussion section.

\section{Combined effect of defaults and incentives}

The results presented in the two experiments reflected the effect of default options when no other programmes were specifically in place to encourage children to 
consume fruits and vegetables. Our results suggest that in the absence of other interventions, the use of a default option was neither an effective nor a cost-efficient way of increasing fruit and vegetable consumption. However, we also collected similar data for the two school districts with different policies during a separate $5 \mathrm{~d}$ period at each school in which we provided a small reward to children for eating at least one serving of fruits or vegetables. Past studies show that rewards programmes can create large increases in fruit and vegetable consumption in schools ${ }^{(14,21)}$. In Table 3 and Fig. 1, we examine the interactive effect between the rewards programme and the default option.
Figure 1 displays the change in fruit and vegetable consumption and waste when the incentive programme was implemented in both the default and non-default schools. Although consumption increased in both conditions, the schools employing the default saw an increase that was larger by 4 percentage points. In addition, schools with a default option in place experienced a large decrease in waste ( $40 \%$ less) when the incentives were implemented with no change in waste at the schools without a default option. Table 3 presents corresponding regression analysis results. The unit of analysis in Table 3 is the child-day observation. This allows us to control for

Table 3 Regression estimates of the effect on consumption and waste of the interaction between incentives and whether schools had a default option requiring elementary-school students to place fruits or vegetables on their tray at lunchtime

\begin{tabular}{|c|c|c|c|c|c|c|c|c|}
\hline & \multicolumn{4}{|c|}{ Default option in place } & \multicolumn{4}{|c|}{ Default option not in place } \\
\hline & \multicolumn{2}{|c|}{ Ate one serving } & \multicolumn{2}{|c|}{ Servings wasted } & \multicolumn{2}{|c|}{ Ate one serving } & \multicolumn{2}{|c|}{ Servings wasted } \\
\hline & Mean & SE & Mean & SE & Mean & SE & Mean & SE \\
\hline Incentive & $0 \cdot 273^{\star *}$ & 0.009 & $0 \cdot 022^{*}$ & 0.009 & $0 \cdot 265^{\star *}$ & 0.009 & $0.021^{*}$ & 0.009 \\
\hline Incentive $\times$ fruit/vegetable required & $0.036^{\star *}$ & 0.010 & $-0 \cdot 171^{\star *}$ & $0 \cdot 011$ & $0 \cdot 042^{\star *}$ & $0 \cdot 010$ & $-0 \cdot 159^{\star \star}$ & $0 \cdot 010$ \\
\hline Fruit/vegetable required & \multicolumn{2}{|c|}{-} & \multicolumn{2}{|c|}{-} & $-0.044^{\star \star}$ & 0.013 & $0 \cdot 245^{\star \star}$ & $0 \cdot 013$ \\
\hline \multicolumn{9}{|l|}{ Control variables } \\
\hline Grade & \multicolumn{2}{|c|}{$\mathrm{x}$} & \multicolumn{2}{|c|}{$x$} & \multicolumn{2}{|c|}{$x$} & \multicolumn{2}{|c|}{$x$} \\
\hline Sex & \multirow{2}{*}{\multicolumn{2}{|c|}{$\begin{array}{l}x \\
x\end{array}$}} & \multirow{2}{*}{\multicolumn{2}{|c|}{$\begin{array}{l}x \\
x\end{array}$}} & \multirow{2}{*}{\multicolumn{2}{|c|}{$\begin{array}{l}x \\
x\end{array}$}} & \multicolumn{2}{|c|}{$x$} \\
\hline Item popularity† & & & & & & & & \\
\hline Day of the week & \multirow{2}{*}{\multicolumn{2}{|c|}{$\mathrm{x}$}} & \multicolumn{2}{|c|}{$\mathrm{x}$} & \multicolumn{2}{|c|}{$x$} & \multicolumn{2}{|c|}{$\hat{x}$} \\
\hline School size (000s) & & & & & \multicolumn{2}{|c|}{$\mathrm{x}$} & \multicolumn{2}{|c|}{$\mathrm{x}$} \\
\hline School's FRPL rateł & \multirow{2}{*}{\multicolumn{4}{|c|}{ Fixed effects }} & te & & & \\
\hline School controls & & & & & \multicolumn{4}{|c|}{ Random effects } \\
\hline Mean (pre-period) & \multicolumn{2}{|c|}{0.335} & \multicolumn{2}{|c|}{$0 \cdot 272$} & \multicolumn{2}{|c|}{0.335} & \multicolumn{2}{|c|}{$0 \cdot 272$} \\
\hline
\end{tabular}

The unit of analysis is the student-day observation ( $n$ 47414). 'Ate one serving' is the fraction of students who ate at least one serving of fruits or vegetables; 'servings wasted' is the average number of servings that each student threw away. Standard errors are clustered at the school-date level.

${ }^{*}$ and ${ }^{* *}$ indicate statistical significance at the $5 \%$ and $1 \%$ level, respectively.

tThe popularity of the most popular item being offered that day.

$\ddagger$ The fraction of children at the school receiving a free or reduced-price lunch.
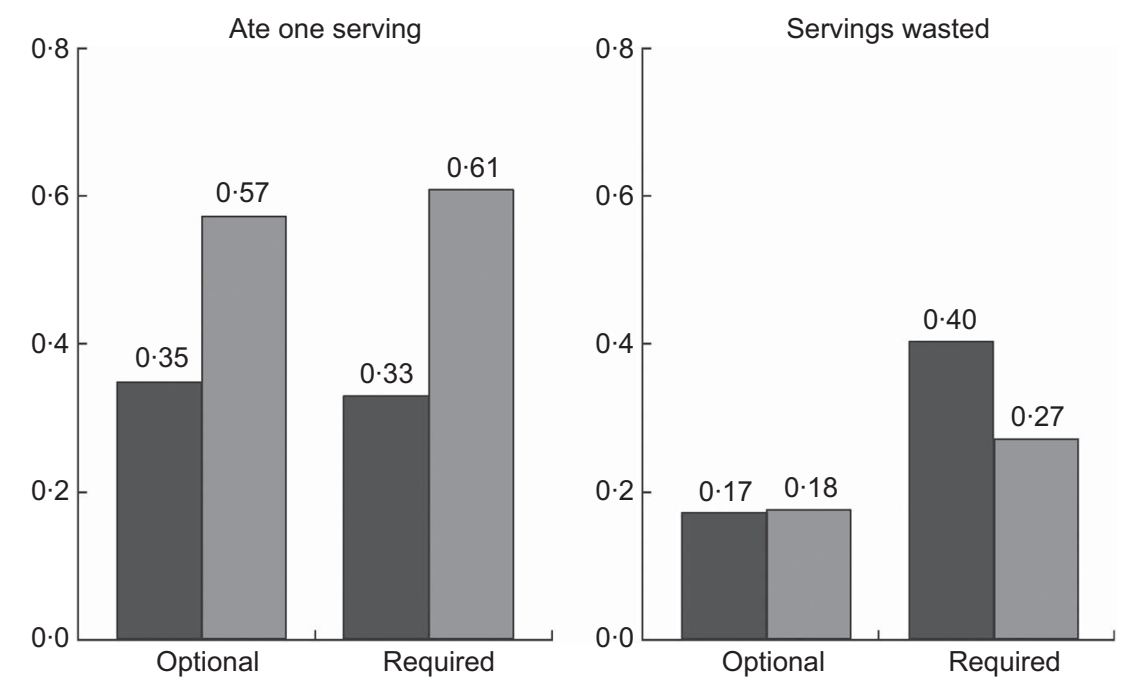

Fig. 1 The interaction of incentives ( $\square$, baseline, no incentives; $\square$, incentives) and requiring elementary-school students to place fruits or vegetables on their tray at lunchtime on consumption and waste. 'Ate one serving' indicates the fraction of students who ate at least one serving of fruits or vegetables; 'servings wasted' represents the average number of servings that each student threw away; 'optional' and 'required' refer to whether students were required to take a serving of fruits or vegetables as part of their school-provided lunch 
the grade and sex of the child, day of the week, characteristics about the school and the items being served that day. We cluster our standard errors at the school-date level. The sample combines data from the baseline and treatment days at each school, providing an overall sample of 47414 child-day observations. The primary focus of Table 3 is the interaction terms between providing an incentive on that day and whether the school had the default option in place. The difference-in-differences approach is justified by the similar consumption rates between districts prior to the start of the incentives $(0.33$ for the default district and 0.35 non-default district) along with the fact that the districts had very similar fractions of students receiving a free or reduced-price lunch and were identical on other important policies that can affect food choices.

We found that at these schools, providing an incentive increased the fraction of children eating fruits and vegetables by 27 percentage points (an $84 \%$ increase). At the schools with the default option in place there was an even larger response to the incentives. There was an additional 3.6 percentage point increase in the fraction of children eating fruits and vegetables, indicating that the presence of the default option produced an even larger effect when using the incentives. Equivalently, these results suggest that default options can successfully increase fruit and vegetable consumption in children but only when coupled with another intervention such as a small rewards programme. In this case, the reward programme may lead the child to consider the fruit or vegetable on his/her tray prior to throwing it away, eventually leading to consumption.

We also estimated a multilevel regression analysis in order to control for school-level variables. This analysis estimates the same equation as in the fixed-effects model, but allows the constant term to be defined by a randomeffects relationship that includes the percentage of students receiving a free or reduced-price meal and the number of students attending the school. This method allows us to better control for variation in school characteristics in our data. We found this approach yielded results that were nearly identical to the fixed-effects model.

When using the school-fixed effects model we cannot estimate the main effect of the default option (since it is a fixed characteristic of each school), so we also estimated our main results using a random-effects model. We found similar effects for providing incentives and also that the incentives were more effective when there was a default option in place. However, we now saw that in the absence of any incentives, the default option was associated with a slightly lower consumption rate ( 4.4 percentage points) and a much higher waste rate (an additional $0 \cdot 22$ servings thrown away per child). Comparing the main effect of default options with the interaction term between the incentives and default options $(0 \cdot 220 v,-0 \cdot 135)$ indicates that most of the extra waste created by using a default option is prevented by providing a small incentive.

\section{Discussion}

The new school lunch guidelines represent one of the first major applications of default options to food choices in children. With the changes in the school lunch guidelines, schools will need to ensure that every child has a serving of fruit or serving of vegetables on his/her tray in order for it to count as a reimbursable meal. The results in the current paper raise some potential concerns about requiring children to place fruits and vegetables on their tray in the absence of any other interventions designed to encourage them to eat those items. The observed level of waste under this default approach is about twice that observed previously in schools $^{(19)}$. The National School Lunch Program provides lunch to about 31.6 million children each day. Our results suggest that across all these children providing the additional fruit and vegetable items will cost an additional \$US 5.4 million each day, with about \$US 3.8 million worth of these fruits and vegetables being discarded by students into the trash. Other policies may be much more cost-effective. For example, a direct incentive programme would produce a similar level of consumption for just \$US $1 \cdot 1$ million each day ${ }^{(21)}$. Additionally we find some evidence that combining the default with other programmes encouraging fruit and vegetable consumption may be more effective. Programmes such as the 5-a-Day Power Plus or reducing unhealthy options at lunch ${ }^{(22,23)}$ might also see an increased effect when combined with a default option.

In the cross-district setting, one drawback is that the comparison is based on naturally occurring variation in policies between two school districts. This comparison would be biased by any other differences that exist between these two districts. Of note are the differences in the proportion of minority students (29\%v. 16\%) and the average size of the school (576v. 744), where the first number in each comparison corresponds to the schools in the district with the default option. Otherwise the districts are similar, especially regarding policies that affect eating behaviour.

In the within-school setting, one concern is that we are only able to look at the effect at schools that were willing to implement the policy during the middle of the year and prior to any actual requirements to do so. If these schools happen to be the type of schools that expect the default option policy to be the most effective, then the estimates we obtain in the present paper overestimate the changes in behaviour that would occur at the average school. Additionally, all observations are from two school districts. Ideally, it would be desirable to cluster standard errors at the district level in order to account for district-specific variation. 
Given that only two districts participated in the study this is not possible.

Within the current study we have implemented only one portion of the new school lunch guidelines - the requirement that a serving of fruit or vegetables be served with each school lunch. Further restrictions on the other foods available may make eating fruits and vegetables more attractive. Future planned restrictions on à la carte items may enhance this effect. Clearly more work is required to determine the full impact of the new school lunch guidelines on consumption and waste of fruits and vegetables.

One overall shortcoming with the present research is that we can only make provisional statements on longterm benefits of the programme. In analyses not included herein, we found weak evidence for a novelty effect from the introduction of the default; i.e. the default increases fruit and vegetable consumption initially but loses potency over time. If the default option increases consumption through a novelty effect, then default options would actually be more costly over time as the novelty disappears.

\section{Conclusion}

We found that requiring a fruit or vegetable as part of the school lunch may increase waste substantially while only modestly increasing consumption of fruits and vegetables. Our results highlighted the fact that default options can be effectively coupled with other interventions in order to increase the efficacy of both approaches. In the present paper, we looked specifically at the combination of a default option with a small rewards programme and found the combined effect of both approaches provided a larger effect than either one implemented individually and a significantly larger effect than the default option alone. As schools begin to implement the new lunch guidelines, they should consider additional approaches to ensure that the potential effects of default options do not go to waste.

\section{Acknowledgements}

Sources of funding: This research was supported by a research grant provided by the US Department of Agriculture's Economic Research Service Division, as part of one of its competitive grants programmes. The funders had no role in shaping the experimental design, data collection or analysis, writing of the report, or the decision to submit the article. Conflicts of interest: There are no potential conflicts of interest on the part of either of the authors. Ethics: This research was approved by the Institutional Review Board at Brigham Young University. Authors' contributions: Both D.J. and J.P. were involved in the conception and design of the studies, acquisition of the data, data analysis and drafting/revising the manuscript. Acknowledgements: The authors are grateful for the excellent research assistance provided by Jason Cook, Jesse Lund, Jeff Swigert and Nick Wilson.

\section{References}

1. Johnson EJ \& Goldstein DG (2003) Do defaults save lives? Science 302, 1338-1339.

2. Choi JJ, Laibson D, Madrian BC et al. (2003) Optimal defaults. Am Econ Rev 93, 180-185.

3. Kahneman D, Knetsch JL \& Thaler R (1991) Anomalies: the endowment effect, loss aversion and the status quo bias. J Econ Perspect 5, 193-206.

4. Samuelson W \& Zeckhauser R (1988) Status quo bias in decision-making. J Risk Uncertain 1, 7-59.

5. Johnson EJ, Bellman S \& Lohse GL (2002) Defaults, framing and privacy: why opting in-opting out. Mark Lett 13, $5-15$.

6. Dillon MS \& Lane HW (1989) Evaluation of the offer vs. serve option within self-serve, choice menu lunch program at the elementary school level. J Am Diet Assoc 89, 1780-1785.

7. Rasmussen M, Krolner R, Klepp KI et al. (2006) Determinants of fruit and vegetable consumption among children and adolescents: a review of the literature. Part I: quantitative studies. Int J Behav Nutr Phys Act 3, 22.

8. Perry CL, Mullis RM \& Maile MC (1985) Modifying eating behavior of young children. $J$ Sch Health 55, 399-402.

9. Wansink B, Just DR, Payne CR et al. (2012) Attractive names sustain increased vegetable intake in schools. Prev Med $\mathbf{5 5}$, 330-332.

10. Just DR, Wansink B, Mancino L et al. (2008) Behavioral Economic Concepts to Encourage Healthy Eating in School Cafeterias. Economic Research Report no. ERR-68. Washington, DC: US Department of Agriculture, Economic Research Service.

11. Cullen KW, Baranowski T, Owens E et al. (2003) Availability, accessibility, and preferences for fruit, 100\% fruit juice, and vegetables influence children's dietary behavior. Health Educ Behav 30, 615-626.

12. Adams M, Pelletier R, Zive $M$ et al. (2005) Salad bars and fruit and vegetable consumption in elementary schools: a plate waste study. J Am Diet Assoc 105, 1789-1792.

13. Robinson-O'Brien R, Story M \& Heim S (2009) Impact of garden based youth intervention programs: a review. $J \mathrm{Am}$ Diet Assoc 109, 273-280.

14. Lowe C, Horne P, Tapper K et al. (2004) Effects of a peer modelling and rewards-based intervention to increase fruit and vegetable consumption in children. Eur J Clin Nutr $\mathbf{5 8}$, 510-522.

15. Stables GJ, Subar AF, Patterson BH et al. (2002) Changes in vegetable and fruit consumption and awareness among US adults: results of the 1991 and 19975 A Day for Better Health Program surveys. J Am Diet Assoc 102, 809-817.

16. French SA, Jeffery RW, Story $M$ et al. (2001) Pricing and promotion effects on low-fat vending snack purchases: the CHIPS Study. Am J Public Health 91, 112-117.

17. US Environmental Protection Agency (2009) Municipal Solid Waste Generation, Recycling, and Disposal in the United States: Facts and Figures for 2008. http://www. epa.gov/epawaste/nonhaz/municipal/pubs/msw2008rpt.pdf (accessed November 2009).

18. Kantor L (1998) A Dietary Assessment of the US Food Supply: Comparing Per Capita Food Consumption with Food Guide Pyramid Serving Recommendations. 
Report no. 772. Washington, DC: Food and Rural Economics Division, Economic Research Service, US Department of Agriculture.

19. Getlinger MJ, Laughlin C, Bell E et al. (1996) Food waste is reduced when elementary-school children have recess before lunch. J Am Diet Assoc 96, 906-908.

20. Swanson M (2008) Digital photography as a tool to measure school cafeteria consumption. J Sch Health 78, 432-437.
21. Just D \& Price J (2013) Using incentives to encourage healthy eating in children. J Human Resour (In the Press).

22. Perry CL, Bishop DB, Taylor G et al. (1998) Changing fruit and vegetable consumption among children: the 5-a-Day Power Plus program in St. Paul, Minnesota. Am J Public Health 88, 603-609.

23. Kubik MY, Lytle LA, Hanna PJ et al. (2003) The association of the school food environment with dietary behaviors of young adolescents. Am J Public Health 93, 1168-1173. 